\title{
Toward understanding the role of p53 in cardiovascular diseases
}

\author{
Mohanalatha Chandrasekharan ${ }^{1}$, Silvia Vasquez ${ }^{2}$, Rajesh Kumar Galimudi ${ }^{3}$, Prashanth Suravajhala ${ }^{1}$ \\ ${ }^{1}$ Bioclues.org, IKP Knowledge Park, Secunderabad, India \\ ${ }^{2}$ Instituto Peruano de Energía Nuclear, Centro Nuclear RACSO, Lima, Perú \\ ${ }^{3}$ Department of Genetics, Osmania University, Hyderabad, India \\ Email: mona@bioclues.org, svasquez@ipen.gob.pe, rajeshgkumar26@gmail.com, prash@,bioclues.org
}

Received 14 November 2012; revised 15 December 2012; accepted 22 December 2012

\begin{abstract}
Tumour suppressor protein 53 (TP53 or simply p53) is a well known protein linked to apoptosis, cell signalling, cascading and several myriad functions in cells. Many diseases are linked to p53 though analysis show only 216 interaction partners. Whether p53 plays an important role in cardiovascular diseases (CVD) remains uncertain. Through this bioinformatical analysis, we propose that $\mathbf{p} 53$ might play a major role in CVD whilst being linked to Hypoxia and Lupus. There could be evidence by pull down assay studies. Whether its interactants play a role in CVD remains to be studied using experiments, though the interaction maps show possible affect on other diseases.
\end{abstract}

Keywords: TP53; Cardiovascular Disease; Protein-Protein Interactions

\section{INTRODUCTION}

Tumour suppressor protein 53 (TP53 or simply p53) is the common-most gene linked to various diseases. Located on the human chromosome 17(17p13.1), it harbours four domains which play a crucial role in apoptosis $[1,2]$. Recent association and interaction studies of p53 with various diseased proteins have caught interest to researchers [3]. Cardiovascular disease (CVD) is one of the most prevalent diseases worldwide and so there is immense interest in chronic, mitochondrial and agingrelated conditions. For example, proteins, viz. sirtuin (SIRT) family of $\mathrm{NAD}(+)$-dependent deacetylases have recently been known to be emerging as exciting targets for CVD which regulates a variety of enzymes, metabolites, transcription factors, co regulators, and enzymes that regulate several tissues [4]. If in disorder, they result in myocardial dysfunction through the deacetylation of $\mathrm{p} 53$. Upregulated $\mathrm{p} 53$ induces the transition of cardiac hypertrophy to heart failure through the suppression of hypoxia inducible factor-1 (HIF-1), which regulates angiogenesis in the hypertrophied heart. In addition, as p53 is known to promote apoptosis, which in turn is involved in heart failure, p53 might be a key molecule in triggering the development of heart failure from multiple mechanisms $[5,6]$. While p53 can modulate the activity and expression of some other proteins have been recently studied, whether or not there are potentially beneficial effects remains to be understood. The actions of the aging proteins on the CVD have been well studied [7] with important insights into the molecular circuitry of cardiovascular system which raises the prospect that $\mathrm{p} 53$ and its cellular pathways contribute to disease pathogenesis. However, proteins which are forcedly expressed inducing apoptosis and their interaction partners have not been studied and our current study is delved upon understanding those protein interacting partners in treatment of such candidates [8]. During hypoxia, p53 is accumulated and interacts with an approximate 28 specific genes to negatively regulate. It is then phosphorylated at Ser 15 which by virtue of ataxia telangiectasia-mutated pathways (ATM) and both Ser15 and Thr18 get activated by CK-1. While the protein binds to $\mathrm{I}_{\mathrm{K}} \mathrm{B}_{\beta}$ and $\mathrm{mSin} 3 \mathrm{~A}$ making hypoxia levels less than $5 \% \mathrm{O}_{2}$, it later enters to the nucleus as a complex with $\mathrm{mSin} 3 \mathrm{~A}$ binding to the MDM2 gene. In the cytoplasm, MDM2 interacts with p53 via AKT and HIF pathways. As HIF proteins family is a regulator of $\mathrm{O}_{2}$ homeostasis, it is known that AKT pathways inhibits $\mathrm{p} 53$-mediated transcription and apoptosis.

\section{METHODS}

Through this study, we exploited the protein interaction partners by showing evidence of DNA damage, activation of damage repair pathways, p53 expression and apoptosis, involving a variety of different cell types with respect to CVD. Genemania [9] and Genecards [10] were searched for $\mathrm{p} 53$ and its interactants in relation to Car- 
diomyopathy, Lupus, Hypoxia and Apoptosis. Genemania analysis recognized 100 closely interacting p53 genes in Homo sapiens of which 11 genes are involved in Hypoxia and 19 in Apoptosis including p53. Genecards analysis identified a total of 1210 genes involved in Lupus and 663 in Cardiomyopathy including p53. The result obtained from Genecards was carefully analysed to restrict the study to p53 and its interactants. Thus the investigation narrowed down to 15 genes for Lupus and 4 for Myopia. As few of these genes show their presence in more than one of the four disorders of our interest, combining the results we had 35 short listed candidates (Please see Table 1) from our first set of analysis. Next we subjected P53 to Osprey visualization [11] and it returned 216 interacting partners (Figure 1). The outcome was compared with the previous analysis and of the 35 genes, 10 (shown by bigger nodes in Figure 2) could be mapped in common. The 35 short listed proteins have been carefully segregated and annotated for subcellular location and their coexistence for mapping these proteins across the diseases [12]. TargetP [13,14] and WolfPSORT [15] were supplemented for Homologene mapping and Subcellular location prediction and a consensus was reached between them. Subcellular location prediction was used to check the two proteins, if interacting would lie in the same organelle (Please see Table 2).

Table 1. Homologene mapping and p53 as a root reference to proteins interactions.

\begin{tabular}{|c|c|c|c|c|}
\hline Gene & Hypoxia $(\mathrm{H})$ & Apoptosis (A) & Lupus (L) & Cardiomyopathy (C) \\
\hline TP53 & $\mathrm{H}$ & A & $\mathrm{L}$ & $\mathrm{C}$ \\
\hline PML, EP300, PMAIP1, BBC3, SIRT1 & $\mathrm{H}$ & A & & \\
\hline MDM2 & $\mathrm{H}$ & & $\mathrm{L}$ & \\
\hline TP63, CASP2 & & A & & $\mathrm{C}$ \\
\hline MSH2, IFI16, BCL2L1 & & A & $\mathrm{L}$ & \\
\hline MDM4, AQP1, CREBBP, USF1 & $\mathrm{H}$ & & & \\
\hline $\begin{array}{l}\text { AIFM2, PERP, SIVA1, TP53I3, TP73, HIC1, MYBBP1A, } \\
\text { DHCR24 }\end{array}$ & & A & & \\
\hline $\begin{array}{l}\text { HMGN2, NFKBIA, MBD4, APCS, HIC2, HSPA1A, S100B, } \\
\text { PTGS1, MKI67, TYMS }\end{array}$ & & & $\mathrm{L}$ & \\
\hline HMGB1 & & & & $\mathrm{C}$ \\
\hline
\end{tabular}

Table 2. Subcellular location prediction for Homologenes using TargetP and WolfPSORT.

\begin{tabular}{|c|c|c|c|}
\hline Gene & TargetP & WolfPSORT & Consensus \\
\hline TP53 & $\mathrm{N}(1)$ & $\mathrm{N}$ & $\mathrm{N}$ \\
\hline PML, EP300, PMAIP1,BBC3, SIRT1 & $\mathrm{N}$ & $\mathrm{N}$ & $\mathrm{N}$ \\
\hline MDM2 & $\mathrm{N}$ & $\mathrm{N}$ & $\mathrm{N}$ \\
\hline TP63, CASP2 & $\mathrm{N}$ & $\mathrm{N}$ & $\mathrm{N}$ \\
\hline MSH2 & Mitochondria & Plasma Membrane & Mitochondria \\
\hline IFI16, BCL2L1 & $\mathrm{N}$ & $\mathrm{N}$ & $\mathrm{N}$ \\
\hline MDM4, AQP1, CREBBP, USF1 & $\mathrm{N}$ & $\mathrm{N}$ & $\mathrm{N}$ \\
\hline AIFM2, PERP, SIVA1, TP53I3, TP73, HIC1, MYBBP1A,DHCR24 & $\mathrm{N}$ & $\mathrm{N}$ & $\mathrm{N}$ \\
\hline HMGN2, NFKBIA, MBD4, APCS, HIC2, HSPA1A, S100B, PTGS1, MKI67, TYMS & $\mathrm{N}$ & $\mathrm{N}$ & $\mathrm{N}$ \\
\hline HMGB1 & $\mathrm{N}$ & $\mathrm{N}$ & $\mathrm{N}$ \\
\hline $\mathrm{N}=$ Nucleus & & & \\
\hline
\end{tabular}




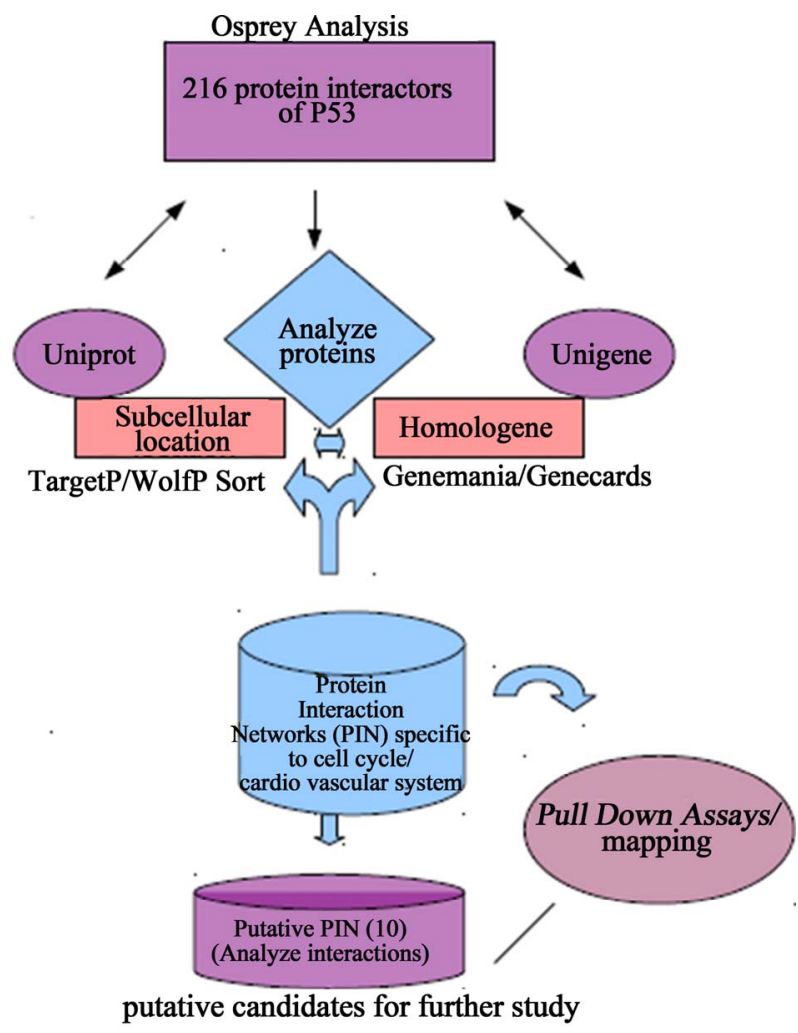

Figure 1. Pipeline showing the annotation strategy in deciphering the knowledge specific to cardiovascular system of P53 and its interactants obtained from osprey evaluation.

\section{RESULTS AND DISCUSSION}

Of all the 216 possible protein interactors using osprey, 10 genes were chosen for further study. The p53 anyways plays a part in all four disorders but whether or not suppression of this protein with respect to a specific disease cause a phenomenal change is not yet understood. Only to understand this, we mapped the 35 short listed proteins (Table 1) on to Osprey and from our annotation we suggest 10 of them (marked by bigger nodes) are putative candidates for the diseases. Furthermore subcellular location confirms their possible role in the cardiovascular system. We also found that $\mathrm{MSH} 2$ is found both in mitochondria and cytoplasm suggesting that the interacting partners of these proteins might also be known in both organelles. Nevertheless, the role of MSH2 in cardiovascular system cannot be turned away as DNA repair system may also be present in CVD.

\section{CONCLUSION}

It is interesting to explore the role of p53 in cardiovascular diseases. Our approach, we believe has narrowed down the experimentation in finding better candidates of p53 in cardiovascular system. While MSH2 is known to be found in both mitochondria and cytoplasm (or nucleus), the subcellular location studies we have employed has given a validation that $\mathrm{MSH} 2$ might also play an

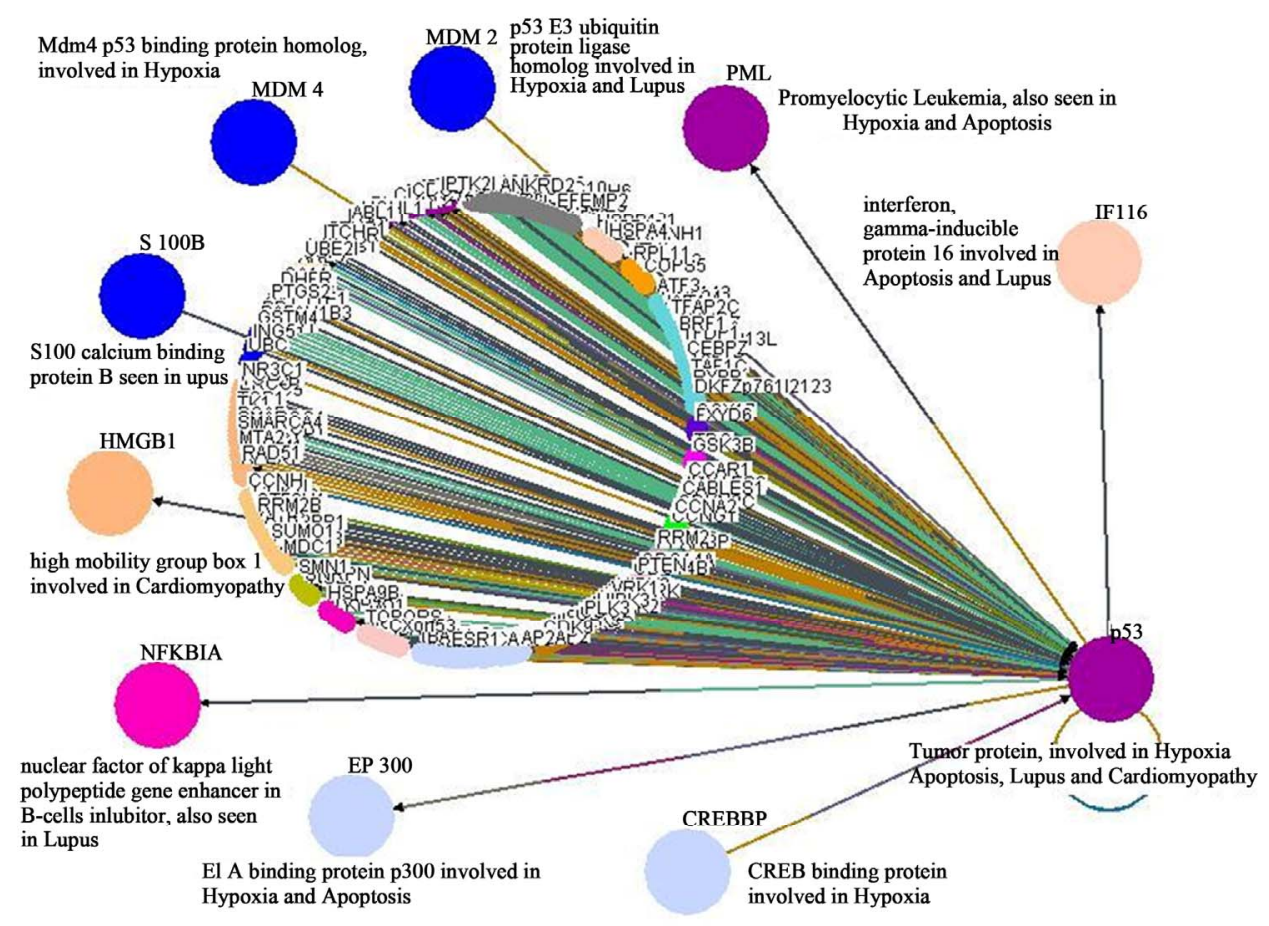

P53 PPI with reference to Hypoxia Apoptosis, Lupus and Cardiomyopathy. An analysis base on Genemania,Genecards and Osprey evaluations. Genemania gives a list of 100 interactants with respect to P53. However only 11 are involved in hypoxia and 19 in apoptosis (including p53). Genecards gives 15 interactants of 1210 entries for Lupus and 4 of 663 for cardiomyopathy (including p53). Of the 35 mcandidates shortlisted from the previous analysis, 10 genes could be mapped common in the osprey evalution.

Figure 2. Putative Protein Interaction Network (PIN) of p53. 
important role in validating the role of these proteins linked to p53, towards CVD. We believe and envisage that the other proteins (highlighted as bold and bigger nodes) are better candidates and it would be interesting to run pull down assays for these proteins to check for their candidacy in CVD.

\section{ACKNOWLEDGEMENTS}

We thank Dr. Tiratha Raj Singh for providing kind inputs.

\section{REFERENCES}

[1] Bai, L. and Zhu, W.-G. (2006) p53: Structure, function and therapeutic applications. Journal of Cancer Molecules, 2, 141-153.

[2] National Center for Biotechnology Information (US) (1998) The p53 tumor suppressor protein. Genes and Disease, National Center for Biotechnology Information (US), Bethesda.

http://www.ncbi.nlm.nih.gov/books/NBK22268/

[3] Levine, A.J. and Oren, M. (2009) The first 30 years of p53: Growing ever more complex. Nature Reviews Cancer, 9, 749-758. doi:10.1038/nrc2723

[4] Borradaile, N.M. and Pickering, J.G. (2009) NAD(+), sirtuins, and cardiovascular disease. Current Pharmaceutical Design, 15, 110-117. doi: $10.2174 / 138161209787185742$

[5] Sano, M. and Komuro, I. (2008) P53 and its role in the development of heart failure. Japanese Journal of Clinical Medicine, 66, 1013-1021.

[6] Sano, M., Minamino, T., Toko, H., Miyauchi, H., Orimo, M., Qin, Y., Akazawa, H., Tateno, K., Kayama, Y., Harada, M., et al. (2007) p53-induced inhibition of hif-1 causes cardiac dysfunction during pressure overload. $\mathrm{Na}$ ture, 446, 444-448.

[7] Tsoporis, J.N., Mohammadzadeh, F., Parker, T.G. (2011) S100B: A multifunctional role in cardiovascular pathophysiology. Amino Acids, 41, 843-847.

\section{doi:10.1007/s00726-010-0527-1}

[8] Mercer, J., Mahmoudi, M. and Bennett, M. (2007) DNA damage, p53, apoptosis and vascular disease. Mutation Research, 621, 75-86.

doi:10.1016/j.mrfmmm.2007.02.011

[9] Warde-Farley, D., Donaldson, S.L., Comes, O., Zuberi, K., Badrawi, R., Chao, P., Franz, M., Grouios, C., Kazi, F., Lopes, C.T., Maitland, A., Mostafavi, S., Montojo, J., Shao, Q., Wright, G., Bader, G.D. and Morris, Q. (2010) The GeneMANIA prediction server: Biological network integration for gene prioritization and predicting gene function. Nucleic Acids Research, 38, W214-W220. doi:10.1093/nar/gkq537

[10] Stelzer, G., Dalah, I., Iny Stein, T., Satanower, Y., Rosen, N., Nativ, N., Oz-Levi, D., Olender, T., Belinky, F., Bahir, I., Krug, H., Perco, P., Mayer, B., Kolker, E., Safran, M. and Lancet, D. (2011) In-silico human genomics with genecards. Human Genomics, 5, 709-717. doi:10.1186/1479-7364-5-6-709

[11] Breitkreutz, B.J., Stark, C. and Tyers, M. (2003) Osprey: A network visualization system. Genome Biology, 4, R22. doi:10.1186/gb-2003-4-3-r22

[12] Nemchenko, A., Chiong, M., Turer, A., Lavandero, S. and Hill, J.A. (2011) Autophagy as a therapeutic target in cardiovascular disease. Journal of Molecular and Cellular Cardiology, 51, 584-593. doi:10.1016/j.yjmcc.2011.06.010

[13] Emanuelsson, O., et al. (2007) Locating proteins in the cell using TargetP, SignalP and related tools. Nature protocols, 2, 953-971. doi:10.1038/nprot.2007.131

[14] Emanuelsson, O., Nielsen, H., Brunak, S. and von Heijne, G. (2000) Predicting subcellular localization of proteins based on their N-terminal amino acid sequence. Journal of Molecular Biology, 300, 1005-1016. doi:10.1006/jmbi.2000.3903

[15] Horton, P., Park, K.-J., Obayashi, T., Fujita, N., Harada, H., Adams-Collier, C.J. and Nakai, K. (2007) WoLF PSORT: Protein localization predictor. Nucleic Acids Research, 35, W585-W587. doi:10.1093/nar/gkm259 